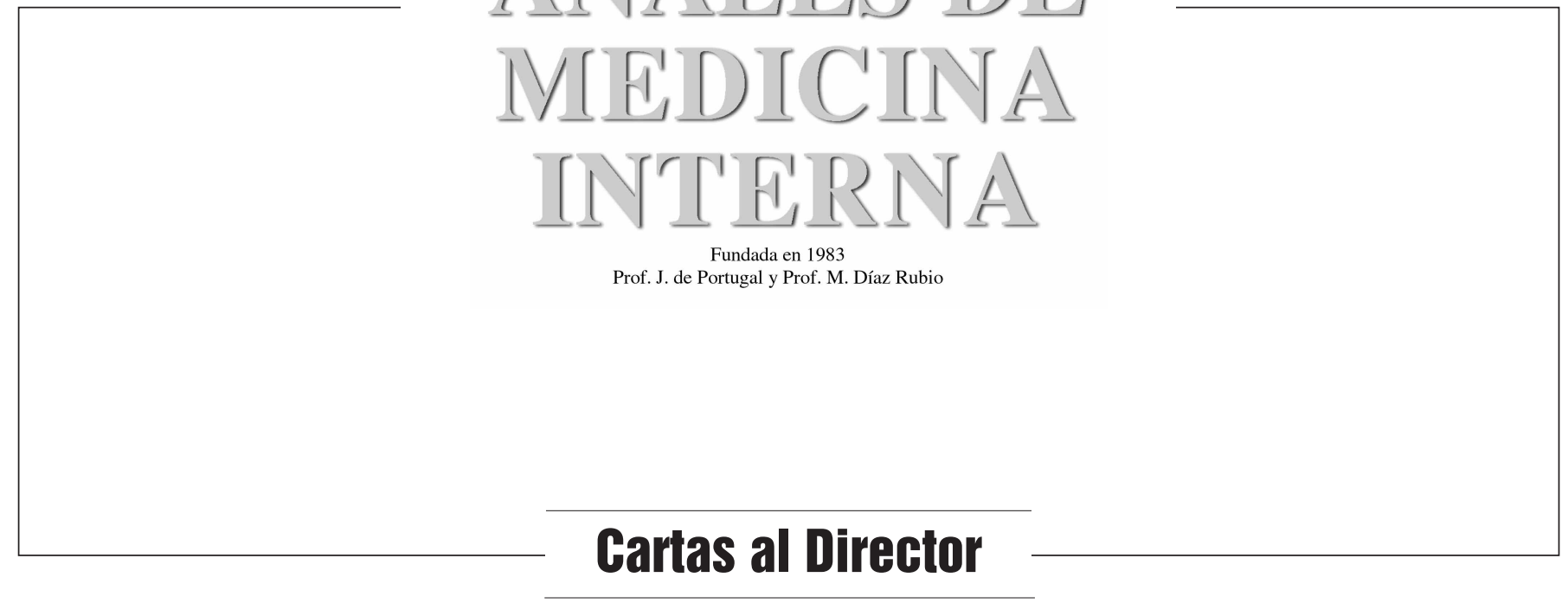

\section{Síndrome de hipersensibilidad a la oxcarbazepina}

\section{Sr. Director:}

El síndrome hipersensibilidad a los epilépticos (SHA) es una reacción grave que cursa con fiebre, rash cutáneo, linfadenopatías y afectación de órganos internos (1). En la gran mayoría de los casos están implicados antiepilépticos aromáticos tales como, la fenitoína, carbamacepina, primidona y fenobarbital. Se presenta el caso de una paciente que tras la toma de oxcarbacepina desarrolló un SHA con afectación cutánea, hepática y pulmonar

Se trata de una paciente mujer de 23 años de edad con antecedentes personales de tetralogía de Fallot intervenida, esquizofrenia paranoide y estar en tratamiento con furosemida, espironolactona, digoxina, ácido acetilsalicílico, escitalopram, mianserina y clonazepan desde hacía varios años. La paciente refiere que recientemente tras ser valorada de nuevo por psiquiatría, se le añade oxcarbacepina a dosis de $600 \mathrm{mg} /$ día, comenzando 10 días después de la primera toma con edema de labios y mucosas, a lo que se añadió posteriormente fiebre de $38{ }^{\circ} \mathrm{C}$, lesiones cutáneas y ligera dificultad respiratoria. A la exploración física destacó la presencia de lesiones cutáneas, consistente en máculas múltiples, confluentes, eritemato-rosáceas de aspecto reticular localizadas en miembros superiores, inferiores y tronco, en la auscultación pulmonar se detectó la presencia de estertores crepitantes secos bibasales. En las pruebas complementarias efectuadas destacó la presencia de 13.300 x $10^{9} / 1$ leucocitos con un $78 \%$ de neutrófilos y un $14 \%$ de linfocitos (muchos de ellos de carácter atípico), unas cifras de GOT de 148 UI/L, GPT: 162 UI/1, GGT: 229 UI/1, LDH de 795 UI/1, una gasometría arterial donde se objetivó una $\mathrm{PO}_{2}$ de $57 \mathrm{mmHg}$ y una $\mathrm{PCO}_{2}$ de $42 \mathrm{mmHg}$ y una radiografía de tórax donde se apreció la existencia de un infiltrado intersticial bilateral de predominio en bases. El resto de estudios (coagulación, serologías víricas, e inmunológicos) fueron normales. Se realizó una biopsia de las lesiones cutáneas que confirmó la existencia de una toxicodermia. Tras la retirada de la oxcarbacepina y la instauración de esteroides sistémicos se comprobó la mejoría progresiva de las lesiones cutáneas, de las alteraciones analíticas, gasométricas y la resolución del infiltrado intersticial bilateral.

Se estima que la frecuencia del SHA es de un caso por cada 1.000-10.000 expuestos (2), si bien esta cifra podría estar infraestimada al no haber unos criterios claramente establecidos. Generalmente esta reacción desmesurada, no guarda relación con la dosis (3) y ocurre entre 1 y 8 semanas después de la toma del antivonvulsionante, como se ha podido comprobar en este caso. Los síntomas más frecuente son la fiebre, el rash, las linfadenopatías y la hepatitis, en nuestro caso llama la atención la ausencia de linfadenopatías, y a la presencia de afectación pulmonar, órgano menos frecuentemente afectado en este síndrome. Su mortalidad se sitúa en un $10 \%$, siendo la causa de muerte la insuficiencia hepática, pero si cursa con hepatitis grave e ictericia la mortalidad puede alcanzar la cifra de un 12 a un $50 \%$ (1). Si bien el SHA se ha asociado a otro tipo de fármacos antiepilépticos, la oxcarbacepina a pesar de ser un fármaco reciente y de relativo grado de seguridad (4), también se ha añadido a lista de antiepilépticos que lo producen como atestiguan varios casos en la literatura (5-6). El tratamiento de elección es la interrupción del tratamiento con el anticonvulsionante, y eso en muchas ocasiones, basta por si solo, para que el cuadro se autorresuelva, aunque en ocasiones, como ha sido el presente caso, ha sido necesaria la administración de esteroides sistémicos. En conclusión, debemos de tener en cuenta que, a la hora de que los profesionales prescriban fármacos antiepilépticos, y a pesar de que los nuevos presenten mayor perfil de seguridad, sería recomendable informar a los pacientes de los posibles riesgos de su administración y seguir de cerca la aparición de complicaciones como la acaecida en este caso.

\section{J. M. Hernández Pérez, C. E. Hernández García ${ }^{1}$}

Sección de Neumología. 'Servicio de Urgencias. Hospital General de La Palma. Breña Alta. Isla de la Palma

1. Durán M, Danés I. Síndrome de hipersensibilidad por antiepilépticos. Med Clin (Barc) 2001; 116: 155-6.

2. Schlienger R, Shear N. Antiepileptic drug hypersensitivity syndrome. Epilepsia 1998; 39 (Supl. 7): 3-7. 
3. Allende M, Izuel M, Urbieta E, Villar I, Carcelén J. Síndrome de hipersensibilidad cruzado entre antiepilépticos: a propósito de un caso. Farm Hosp (Madrid) 2004; 28: 56-8.

4. Arroyo S. Oxcarbacepina. Neurología 2001; 16: 370-5.

5. Bosdure E, Cano A, Roquelaure B, Reynaud R, Boyer M, Virad L, et al.
Oxcarbazepine and DRESS syndrome: A paedratic cause of acute liver failure. Arch pediatr 2004; 11: 1073-7.

6. Pastor-Milán E, Rubert-Gómez M, Vázquez-Gutiérrez F, González V. Oxcarbazepine induced interstitial nephritis in a patient with drug hypersensitivity syndrome. Rev Neurol 2003; 37: 948-50. 